\title{
IMPROCEDENCIA DE LA ACCIÓN DIRECTA DEL TERCERO PERJUDICADO EN CONTRA DEL ASEGURADOR DE RESPONSABILIDAD CIVIL, BAJO EL NUEVO REGIMEN LEGAL CHILENO DEL CONTRATO DE SEGURO
}

\author{
INADMISSIBILITY OF A DIRECT ACTION THE AGAINST LIABILITY \\ INSURER (CASUALTY UNDERWRITER) UNDER THE NEW LEGAL \\ REGIME OF CHILEAN INSURANCE CONTRACT
}

\section{ROBERTO Ríos OSSA*}

\begin{abstract}
RESUMEN: La modificación que la ley 20.667 introdujo al título VIII libro II del Código de Comercio chileno contempló una regulación del seguro de responsabilidad civil. Sobre la base de lo dispuesto en los artículos 570 y 513 letra c), que definen seguro de responsabilidad civil y la figura del beneficiario, alguna doctrina reciente ha sostenido que se encuentra consagrada de modo implícita la acción directa en contra del asegurador de responsabilidad civil en nuestro sistema jurídico. A nuestro juicio, la acción directa no procede en el estado actual de nuestro ordenamiento jurídico.
\end{abstract}

Palabras clave: Seguro de responsabilidad civil, beneficiario, tercero perjudicado, acción directa.

ABSTRACT: The amendment introduced by law 20.667 to the Chilean Commerce Code contemplates regulation of liability insurance. Based on the provisions of the Articles 570 and 513 letter c ), a recent doctrine has held an implied recognition of a direct action in our system legal. In our view, direct action is not recognized in the current state of our legal system.

Key words: Civil liability insurance, injured third party, direct action, beneficiary.

\section{INTRODUCCIÓN}

La acción directa en el seguro de responsabilidad civil, es la acción que posee la víctima de un daño en contra de quien asumió un riesgo de responsabilidad en calidad de asegurador ${ }^{1}$. Se trata de un instrumento que algunos ordenamientos jurídicos han incorporado con el objeto de tutelar -o garantizar- la reparación del daño sufrido ${ }^{2}$ por un

\footnotetext{
Profesor de Derecho Comercial Pontificia Universidad Católica de Chile. Doctor en Derecho UC. Miembro de la Asociación Internacional de Derechos del Seguro (AIDA), sección chilena. Dirección Postal: Facultad de Derecho, Avenida Libertador Bernardo O’Higgins 340, tercer piso, comuna de Santiago, Chile. Correo electrónico: rrioso@uc.cl

1 Sobre el concepto doctrinal de acción directa véanse Veiga (2013) pp. 40 y ss.; Contreras (2014) p. 432.

2 La ley de contrato de seguro española (en adelante LCS) consagra expresamente la acción directa en su artículo 76 para todos los seguros de responsabilidad civil. Se trata de una acción de iure proprio, por estar
} 
perjudicado, siguiendo con ello, la tendencia de la denominada socialización del derecho de daños ${ }^{3}$.

En el contexto de nuestro ordenamiento jurídico, el 1 de diciembre del año 2013 entraron en vigencia las modificaciones introducidas por la ley 20.667 al título VIII libro II del Código de Comercio chileno (en adelante C.com). Nuestro legislador sistematizó la regulación del contrato de seguro en tres secciones ${ }^{4}$. La segunda sección se refiere a los seguros de daños y el \& 4 trata "Del seguro de responsabilidad civil" (arts. 570 y ss.).

Es ineludible señalar que durante la tramitación parlamentaria del proyecto que terminó en la ley 20.667, uno de los tópicos más debatidos fue la regulación del seguro de responsabilidad civil y, en especial, la instauración en nuestro sistema jurídico de la denominada acción directa. Por otra parte, una supuesta falta de claridad en las referidas modificaciones, ha impulsado un debate doctrinal sobre la procedencia o no de la acción directa en nuestro ordenamiento jurídico. Debemos considerar que la posibilidad de ejercer la acción directa en contra del asegurador de responsabilidad civil, provocaría un cambio sustancial tanto en el denominado derecho de daños como en el seguro que ampara un riesgo de esta naturaleza. En este sentido, es en el ordenamiento jurídico chileno y en concreto en la regulación del seguro de responsabilidad civil, donde se centrará nuestro trabajo.

El presente trabajo se contextualiza en la formulación de una propuesta de interpretación de base dogmática e histórica, de las normas contenidas en las modificaciones introducidas por la ley 20.667 al título VIII, libro II del Código de Comercio chileno, en concreto sobre el aseguramiento de la responsabilidad civil, con el objeto de demostrar que nuestro ordenamiento Jurídico no contempla la acción de directa del tercero perjudicado en contra del asegurador de responsabilidad civil.

Para los efectos de nuestra propuesta, previamente revisaremos de manera panorámica la evolución e influencia recíproca entre responsabilidad civil y seguro, en una primera parte (II); luego, veremos la implementación en los ordenamientos jurídicos de tradición continental de mecanismos de tutela a favor de las víctimas del daño, en una segunda parte

desvinculada de la relación contractual entre el asegurador y el asegurado. Esta autonomía se consolida por ser inmune la acción directa que ejerce el tercero perjudicado, a las excepciones que el asegurador pueda ejercer en contra. El régimen de excepciones que regula la norma española que hemos citado, no excluye la concurrencia de determinados presupuestos básicos para el ejercicio de la acción directa, como la existencia del hecho dañoso y la consecuente responsabilidad del asegurado. A diferencia del sistema español, el italiano no contempla una norma transversal como la del artículo 76 de la LCS. En Italia se contempla la figura de pago directo de la indemnización al perjudicado, facultad que se concede al asegurador en el artículo 1917 del Codice civile, pero se sigue tratando de un contrato en interés del asegurado y no en favor del tercero. En consecuencia, la víctima no tiene una posición jurídica autónoma, no está legitimado para ejercer una acción directa en contra del asegurador. El tercero perjudicado en palabras de VOLPE "es y sigue siendo tercero respecto del contrato de seguro de responsabilidad civil, contrato que es estipulado directamente en favor del asegurado y no en función o favor del tercero". Hay matices, en concreto, para ciertos casos de seguros de responsabilidad civil obligatorios, por ejemplo, la circulación vehicular. Véase por todos VolPE (2010) p. 116. En el derecho francés, el artículo L.124-3 del Code de assurances, contempla desde el año 2007 de manera expresa la acción directa del tercero perjudicado, para todos los casos de seguros de responsabilidad civil.

3 Véase Díez-Picazo (2011) pp. 135 y ss.

4 En cuanto a las modificaciones introducidas por la ley 20.667 al título VIII libro II del C.com. véanse: Arellano (2014) pp. 8 y ss.; Contreras (2014) pp. 13 y ss.; Hoyl y Ruiz -Tagle (2014) pp. 1 y ss.; Ríos (2015) pp. 5 y ss. 
(III), para finalmente, y en una tercera parte, analizar el estado actual de nuestra legislación y doctrina (IV), con el fin de demostrar la improcedencia de la acción directa en contra del asegurador del responsabilidad civil en nuestro Derecho, como hemos adelantado (V).

\section{LA RESPONSABILIDAD CIVIL Y SU ASEGURAMIENTO: EVOLUCIÓN E INFLUENCIA RECÍPROCA}

Los Códigos de Comercio decimonónicos no contemplaron una regulación expresa del seguro de responsabilidad civil ${ }^{5}$ por razones de origen histórico. Como señala Reglero CAmpos, "la importancia actual del seguro de responsabilidad civil no se corresponde con su escaso desarrollo en la época de la codificación" 6 . No obstante, podemos encontrar un germen del aseguramiento del riesgo de responsabilidad civil en el seguro marítimo, específicamente en la responsabilidad por abordaje $\mathrm{y}^{7}$ en los seguros sobre reclamación de vecinos y del riesgo locativo ${ }^{8}$.

La doctrina coincide en que el inicio del seguro de responsabilidad civil como un tipo contractual específico dentro del denominado derecho de seguros, surge de la mano del desarrollo y acrecentamiento de las actividades riesgosas de la segunda mitad del siglo $\mathrm{XIX}^{9}$, en particular, aquellas consideradas como fuentes de riesgos y accidentes de relevancia. Ejemplo de estas actividades fueron aquellas relacionadas con la circulación vehicular, ferroviaria (por daños corporales causados a personas o a mercaderías en el transporte) y los accidentes del trabajo ${ }^{10}$. Según Viterbo, "donde el seguro de responsabilidad civil encuentra su terreno propicio es, en especial, el de los transportes modernos y el automovilismo" 11 .

Este incipiente aseguramiento de la responsabilidad civil se enfrentó a ciertos obstáculos o resistencias. La primera dificultad manifestada por la doctrina, fue el argumento de ser ilícito e inmoral liberarse contractualmente de las consecuencias de la propia culpa (ne culpa praestetur) ${ }^{12}$. Un segundo impedimento se sustentó en la supuesta ilicitud de asegurar hechos culposos, por cuanto el riesgo era entendido como la ocurrencia de un caso fortuito $^{13}$. Unido a lo anterior, encontramos como argumento impeditivo de este tipo

5 Haftoflichtversicherung para los alemanes, Assurances de la responsabilité civile para los franceses, Assicurazioni delle responsabilita civile para los italianos.

6 Reglero Campos (2006) p. 723.

7 Véanse: Viterbo (1944) p. 23; Donati (1954) p. 323; Garrigues (1982) p. 360; Sánchez Calero et al. (2010) pp. 1590 y ss.

8 Véase Viterbo (1944) pp. 52 y ss.

9 Véase por todos Calzada Conde (1983) p. 30.

10 Véanse Viterbo (1944) p. 11; Donati (1954) p. 323; Picard y Besson (1964) p. 488; Jaboc (1974) p. 233.

11 Véase Viterbo (1944) p. 54. Fue la ley alemana sobre responsabilidad civil de las compañías que explotan líneas ferroviarias de 1871, la que reguló de modo específico este tipo de seguro. En este sentido véase EICHLER (1966) p. 261.

12 Véase Por todos ЈАСОв (1974) p. 233.

13 Ríos (2010) p. 516. De acuerdo a lo prescrito en el artículo 513 del Código de Comercio anterior a las modificaciones del año 2013, se entiende por riesgo la eventualidad de todo caso fortuito que pueda causar la pérdida o deterioro de los objetos asegurados. Esta definición fue criticada por la doctrina, ya que el riesgo quedaría circunscrito en el evento fortuito, desechando así la posibilidad de asegurar riesgos que provengan de conductas culposas del asegurado, por consiguiente excluyendo la posibilidad de asegurar el riesgo de 
Ríos Ossa, Roberto — "Improcedencia de la acción directa del tercero perjudicado en contra del asegurador..."

de aseguramiento, el supuesto espiral de ocurrencia del daño por la teórica displicencia del causante del menoscabo, al existir un amparo frente a la posibilidad de tener que responder con el propio patrimonio frente a un daño causado a otro ${ }^{14}$.

No obstante los obstáculos iniciales enunciados, el desarrollo socioeconómico del hombre fue generando nuevos riesgos asociados a nuevas actividades de diversa índole. Hay un aumento exponencial del riesgo unido a actividades que tienen por fin producir un mayor bienestar al ser humano, que paradójicamente son susceptibles de provocar un daño a $\operatorname{otros}^{15}$.

La responsabilidad civil y su aseguramiento se han desarrollado de manera recíproca. Ambos se centran en un mismo elemento y fin: el daño y su reparación ${ }^{16}$. La responsabilidad civil y el seguro han evolucionado desde una atención exclusiva en la tutela del patrimonio del asegurado hasta convertirse, además, en un instrumento de tutela de los derechos de los perjudicados o víctimas del daño. Esta interferencia recíproca o interacción entre la responsabilidad y el seguro, ha provocado que a "mayor responsabilidad, se ha producido un incremento en el seguro, y a ese aumento ha seguido otro de la responsabilidad" 17 .

Será al alero de la responsabilidad objetiva o de la objetivación de la responsabilidad, que el seguro se abrirá camino y encontrará una mayor aceptación ${ }^{18}$. En opinión de Russo, el derecho de la responsabilidad civil se desarrollará sobre la base de dos grandes orientaciones: la objetivación de la responsabilidad y el aseguramiento de la responsabilidad civil, todo con el fin de facilitar la reparación de los daños ${ }^{19}$.

En el contexto que hemos descrito, el establecimiento de instrumentos legales de protección a favor de los terceros perjudicados o víctimas de un daño pareciera una tendencia irreversible. A continuación, analizaremos desde una visión general, como han evolucionado los sistemas jurídicos en este afán tutelar, para luego verificar si nuestro ordenamiento Jurídico ha seguido esta tendencia.

responsabilidad civil. Véanse BAEZA (2001) p. 70; Achurra (2005) pp. 26-27; SANDoval (2007) pp. 189-190; LaGos (2014) p. 987. En el derecho colombiano, por todos Díaz Granados (2008) p. 288.

14 En este sentido véanse: Donati (1954) p. 324; Ver Garrigues (1982) p. 361; Sánchez Calero (2010) p. 1595 .

15 En este mismo sentido véase López-Coвo (1999) p. 5.

16 Mazeaud y Tunc (1963) p. 289. Advierte Sánchez Calero que "la obligación del asegurador al pago de la indemnización en el seguro de responsabilidad civil tiene como presupuesto la existencia de una deuda de responsabilidad civil a cargo del asegurado, pero una y otra obligación son en principio diversas”. SÁNCHEZ Calero (2010) p. 1596. Véase en este sentido Veiga (2013) pp. 18-53.

17 Véase López-Cobo (1999) p. 7; en el mismo sentido Barros (2007) p. 1077; Sánchez Calero (2010) p. 1595; MaYauX (2011) p. 258.

18 Véanse Donatti (1954) p. 325; La Torre (1971) pp. 527 y ss; Cavallo (2007) pp. 3 y ss.; Mayaux (2011) pp. 257 y ss.

19 Russo (2001) p. 2; Véase Díez-Picazo (2011) pp. 167 y ss. 


\section{LA TUTELA DEL INTERÉS DEL PERJUDICADO O VÍCTIMA DEL DAÑO}

En nuestra opinión, el desarrollo de la responsabilidad y su orientación en la búsqueda de un objetivo reparador, impulsó la creación de sistemas de responsabilidad objetivo u objetivada vía jurisprudencial ${ }^{20}$, al aseguramiento obligatorio de la responsabilidad civil, el establecimiento de mecanismos de garantía en favor del perjudicado, y finalmente, la implementación de mecanismos de reclamación directa de las víctimas en contra del asegurador del riesgo de responsabilidad ${ }^{21}$.

Si analizamos los cambios introducidos en los sistemas legales de tradición continental, podremos verificar que la implementación de estos mecanismos de protección en favor de los afectados ha sido de forma secuencial ${ }^{22}$. En primer lugar, se crearon por vía legislativa o jurisprudencial sistemas de responsabilidad objetiva o de culpa presunta respecto de actividades de mayor riesgo ${ }^{23}$. Luego, los legisladores impusieron como presupuesto o requisito para el desarrollo de determinadas actividades riesgosas la contratación de seguros de responsabilidad civil, que confieren cobertura sobre el riesgo que envuelve la actividad del asegurado ${ }^{24}$, con el fin de garantizar a los perjudicados la existencia de un deudor solvente frente a la declaración de responsabilidad del causante del daño. Como sostienen IRIARTE y CASADO, "existe una obligación legal que impone al deudor intermedio la carga de suscribir un seguro de carácter obligatorio que cubra determinados riesgos y que, por lo tanto, garantice al tercero perjudicado o damnificado la compensación económica del daño sufrido" 25 .

Encontraremos diversos mecanismos destinados a tutelar el crédito indemnizatorio de los perjudicados, además de la implementación de instrumentos de reclamación directa en contra del asegurador, los que irán desde la acción subrogatoria como solución jurisprudencial tomada del derecho de obligaciones ${ }^{26}$, los mecanismos de privilegio del crédito del

20 En materia de responsabilidad civil la tendencia general es a la objetivización. JiménEz (2009) p. 742 . Es opinión de Sánchez Calero, que la objetivización de la responsabilidad, "significa en definitiva inclinar la balanza de la justicia en favor del dañado”. Sánchez Calero (2010) p. 1598. Por su parte, López-Cobo señala que "la objetivación surge así como una exigencia social, en virtud de la exposición continuada por parte del individuo al riesgo que supone el uso habitual y generalizado de ciertas máquinas, bienes, instalaciones, productos etc.”. López-Сово (1999) p. 6.

21 A juicio de Donati, los casos de responsabilidad objetiva y por culpa presunta abren al camino al derecho objetivo del aseguramiento de la responsabilidad civil. Donatti (1954) p. 325. Por su parte, SánChez Calero señala que "El seguro de responsabilidad civil ha favorecido también la extensión de la objetivización de la responsabilidad y viceversa”. SÁnCHeZ CALERo (2010) p. 1597.

22 Véanse en este sentido La Torre (1971) pp. 527 y ss.; Clavero (1995) p. 11.

23 Sobre la relación entre la responsabilidad civil objetiva y su aseguramiento véanse TrIMARCHI (1961) pp. 30 y ss.; Alpa y Bessone (2001) pp. 520 y ss.

24 Según Olivencia, "la protección de la víctimas y la reparación del daño, una vez causado, no solo exigen un régimen especial de responsabilidad (carácter objetivo de ésta y determinación subjetiva del responsable) sino su cobertura, por un régimen de garantía obligatoria, que permita hacer efectiva, al menos hasta cierto límite, la indemnización a los perjudicados”. Olivencia (2002) p. 20. En este mismo sentido véanse Russo (2001) p. 24.; Lambert-Faivre y Leveneur (2005) p. 13; Bataller, Latorre y Olavarría (2007) p. 274.

25 IRIarte y Casado (2013) p. 18.

26 La jurisprudencia francesa sostuvo que de acuerdo al derecho común el asegurado podría dirigirse en contra del asegurador, por la vía de la acción oblicua en conformidad al artículo 1166 del Code civil. MAZEAUD y 
Ríos Ossa, Roberto — "Improcedencia de la acción directa del tercero perjudicado en contra del asegurador..."

tercero sobre la suma asegurada, hasta la acción directa como un derecho de iure proprio ${ }^{27}$ en favor de perjudicado, para exigir directamente al asegurador la reparación del daño ${ }^{28}$. En opinión de Carboni, "la formula asegurador de la responsabilidad, conlleva la responsabilidad del asegurador" 29 , afirmación que coincide con la tendencia a considerar este tipo de seguros, como un instrumento de reparación del daño, además de ser un mecanismo de protección o amparado de la integridad del patrimonio propio.

En consecuencia, el seguro de responsabilidad civil experimentará una profunda transformación en el tiempo, especialmente en sus fines, que en su inicio se limitaban a tutelar los intereses del contratante o asegurado ${ }^{30}$, para exigirse luego, como sostiene PASANISI, objetivos supra-contractuales que se identifican con la denominada socialización del seguro de responsabilidad civil $^{31}$. Por esta razón, el seguro de responsabilidad civil no solo constituirá un mecanismo de protección frente al pasivo que puede provocar en el patrimonio del asegurado la deuda de responsabilidad, sino además, una garantía de indemnización a favor de la víctima del daño ${ }^{32}$.

A continuación, abordaremos como nuestro legislador trata la regulación del seguro de responsabilidad civil en el Código de Comercio, con el objeto de determinar si consideró la acción directa como una acción de iure proprio, autónoma e independiente y de fuente legal, en las modificaciones introducidas por la ley 20.667.

Tunc (1963) p. 291; en el mismo sentido Russo (2001) p. 31. Este mecanismo fue calificado de insuficiente, ya que la acción oblicua permite el aumento del patrimonio del asegurado, sobre el cual tienen intereses otros acreedores, por lo que la pretensión resarcitoria del tercero perjudicado se puede ver frustrada frente a la de otro acreedor con mejor derecho. PiCARD y BESSON (1964) p. 55; en el mismo sentido Russo (2001) p. 31; LAMBERTFaivre y LeVeneur (2005) pp. 527-528. En este contexto, Russo sostiene que el supuesto descrito llevará a "repensar las relaciones entre asegurador, asegurado y víctima, por lo que el crédito de indemnización del seguro, no debería ser considerado como un crédito ordinario”. Russo (2001) p. 31.

27 Sánchez Calero (2010) p. 1722; en el mismo sentido STiglitz (2005) p. 474.

28 Véase Olivencia (2002) p. 22. El reconocimiento del derecho del perjudicado para exigir la reparación directamente del asegurador "representa la culminación de un largo proceso dentro del seguro de responsabilidad civil, tendiente a tutelar de manera efectiva ese derecho". SánCHEZ CALERO (2010) p. 1723; en el mismo sentido Reglero Campos (2006) p. 791; Clavero (1995) p. 9. La tendencia a nivel de Comunidad Económica, será centrarse en la víctima. Sobre ello Jiménez Blanco señala que "el Reglamento de Roma II (Reglamento CE N 864/2007 del Parlamento Europeo y del Consejo del 11 de julio de 2007, relativo a la ley aplicable a las obligaciones extracontracuales) se ocupa expresamente de la acción directa en su artículo 18. El tratamiento que este Reglamento dispensa que las acciones directas deben enmarcarse en el contexto del instrumento, basada en el criterio general de la ley del daño (art. 4.1), que se inspira más en la idea de reparación, que en la regulación de conductas y de castigo de los comportamientos culpables [...]”. JiménEZ (2009) pp. 741-742.

29 Carboni (1972) p. 499.

30 Tradicionalmente el seguro de responsabilidad civil ha sido considerado como un seguro de reembolso. Calzada Conde (2005) p. 14.

31 Pasanisi (1970) p. 190; en el mismo sentido Carboni (1972) p. 498; López-Cobo (1999) p. 7; Veiga (2013) p. 58. En este sentido, el autor del proyecto de ley, Osvaldo Contreras, en su intervención durante la tramitación legislativa, señaló: "Estimó indispensable mantener el Artículo 572 original del proyecto, porque éste contempla explícitamente la referida acción directa, que es una alternativa que beneficia enormemente al asegurado y hace realidad la función social que el seguro tiene, al beneficiar al mismo tiempo al tercero y concederle acción para reclamar la indemnización.”. Véase historia de la ley 20.667, p. 99.

32 En este sentido véanse Lambert-Faivre y Leveneur (2011) p. 485; Abravanel-Jolly (2013) p. 245. 


\section{LA ACCIÓN DIRECTA EN EL DERECHO CHILENO}

\section{PRELIMINAR}

El seguro de responsabilidad civil en nuestro ordenamiento jurídico está regulado en los artículos 570 y siguientes del C.com. Las normas enunciadas se ocupan de definir este tipo contractual en específico, para luego abordar materias relacionadas con el aviso del siniestro, la extensión de cobertura, la defensa del asegurado y la prohibición de transacción.

El texto del artículo 570 del C.com. que define el seguro de responsabilidad civil, al disponer que "Por el seguro de responsabilidad civil, el asegurador se obliga a indemnizar los daños y perjuicios causados a terceros, de los cuales sea civilmente responsable el asegurado, por un hecho y en los términos previstos en la póliza”, no renuncia al carácter patrimonial de este seguro de daños ${ }^{33}$. El riesgo asegurable lo constituye el evento de una deuda de responsabilidad civil que puede provocar una disminución en el patrimonio del asegurado $^{34}$. El asegurador se obliga a cumplir con su prestación consistente en pagar una indemnización por daños causados a terceros distintos del asegurado, siempre y cuando este último sea civilmente responsable. El origen contractual del seguro de responsabilidad civil, es reafirmado por el legislador al limitar la prestación del asegurador a las delimitaciones cuantitativas y cualitativas pactadas por las partes. En este sentido, la Compañía pagará la indemnización "por un hecho y en los términos previstos en la póliza", según reza la parte final del inciso primero del citado artículo 570 del C.com ${ }^{35}$.

Por otra parte, a nuestro parecer, el inciso segundo del artículo 570 al disponer que “en el seguro de responsabilidad civil, el asegurador pagará la indemnización al tercero perjudicado, en virtud de sentencia ejecutoriada, o de transacción judicial o extrajudicial celebrada por el asegurado con su consentimiento", simplemente reitera la exigencia del inciso primero del mismo artículo, en cuanto a la necesaria concurrencia de uno de los presupuestos que hacen exigible la obligación condicional del asegurador de indemnizar, en el seguro de responsabilidad civil: una sentencia judicial que declare la responsabilidad civil del asegurado u otro equivalente jurisdiccional como lo es una transacción judicial o extrajudicial ${ }^{36}$.

33 En la doctrina francesa, ubica el seguro de responsabilidad civil dentro de los denominados seguros de daños. Picand y Besson (1964) p. 484; JACOB (1974) p. 234.

34 En este sentido Contreras (2014) p. 393; Barrientos (2015) p. 620. El Código Civil italiano regula el seguro de responsabilidad civil en el artículo 1917. Revisado su texto podemos encontrar cierta similitud con el artículo 570 del C.com. por cuanto hace referencia al tercero perjudicado y faculta al asegurador a pagar directamente al tercero con consentimiento del asegurado. No obstante el tenor literal de la norma italiana, la doctrina dominante ha señalado como regla general, que el seguro de responsabilidad civil ampara al asegurado en contra de una deuda de responsabilidad y no constituye un seguro a favor de terceros. El tercero perjudicado no posee una acción autónoma en contra del asegurador, que lo faculte a exigir el pago de la suma asegurada. Véanse CaVallo (2007) p. 9; Volpe (2010) p. 116.

35 La definición del seguro de responsabilidad civil del artículo 570 del C.com, difiere en aspectos sustanciales del texto original de la moción parlamentaria, en concreto al insertar la frase con una sintaxis copulativa por un hecho y en los términos previstos en la póliza.

36 La norma chilena pareciera cercana al texto del artículo 53 de la Ley de seguros francesa de 1930 que disponía lo siguiente: "El asegurador no podrá pagar a otro que no fuera el tercero lesionado cualquier parte de la suma debida por él, mientras que ese tercero no haya sido reembolsado hasta un total de dicha suma, de 
Revisado el artículo 570 del C.com. podemos arribar a una primera conclusión, aunque preliminar: la ley chilena no consagra explícitamente la acción directa en contra del asegurador de responsabilidad civil.

A continuación, analizaremos el estado actual de nuestra doctrina en materia de acción directa en el seguro de responsabilidad civil, para luego contraponerla con nuestra postura, analizando para ello la historia de la ley, por un lado, y por el otro, la norma legal (lege lata) y ciertos tópicos dogmáticos sobre el denominado beneficiario en el contrato de seguro, como también la regla especial de prescripción del artículo 541 del C.com.

\section{ESTADO DE LA DOCTRINA NACIONAL}

Frente a nuestra posición sobre la improcedencia de la acción directa en nuestro Derecho, es ineludible revisar la propuesta de procedencia de este instrumento de tutela a favor del tercero perjudicado por parte de nuestra reciente doctrina. En concreto, se ha formulado una propuesta de interpretación del artículo 570 del C.com., norma que en una interpretación armónica con el artículo 513 letra c) del mismo Código, permitiría sostener que nuestro Derecho contempla implícitamente una acción directa autónoma, de iure proprio, que posee el tercero perjudicado o víctima del daño en contra del asegurador de responsabilidad civil ${ }^{37}$.

En una primera etapa, y en base a lo dispuesto en los artículos 570 y 513 letra c) del C.com., se sostiene que "En el funcionamiento de los seguros de responsabilidad civil interviene, además, el llamado 'tercero beneficiario', que es la persona que va a recibir la indemnización por el daño que le causó el actuar del asegurado ... [...]”. Esta formulación se sustenta en el citado artículo 513 letra c) del C.com. que define beneficiario como "el que, aun sin ser asegurado, tiene derecho a indemnización en caso de siniestro" ${ }^{38}$. Esta tesis reconociendo el obstáculo del principio de efectos relativos del contrato, propone que mediante una interpretación analógica de los artículos 570 y 513 letra c) del C.com. podría confirmarse la procedencia de la acción directa ${ }^{39}$.

\footnotetext{
las consecuencias pecuniarias del hecho dañoso que haya comportado la responsabilidad del asegurado". Por su parte, el inciso segundo del artículo 570 del C.com. chileno, dispone que: "En el seguro de responsabilidad civil, el asegurador pagará la indemnización al tercero perjudicado, en virtud de sentencia ejecutoriada, o de transacción judicial o extrajudicial celebrada por el asegurado con su consentimiento". El inciso segundo del artículo 570 del C.com. se aparta de la norma francesa. Se observan algunas diferencia estructurales entre ambos preceptos. Claramente el legislador francés buscó introducir una acreencia a favor del tercero perjudicado respecto de la suma asegurada pactada en el contrato de seguro, siguiendo el criterio de la ley de 1913 que contemplaba un privilegio sobre la suma asegurada para el caso de los seguros de accidentes. PICAND y Besson (1964) p. 526. A nuestro juicio, las dificultades que provocó en el sistema francés la incorporación jurisprudencial y doctrinal de la denominada acción directa, llevó finalmente al legislador francés a recoger esta figura tutelar a favor de los terceros perjudicados de modo expreso en el inciso primero del artículo 124-3 del Code des Assurances, mediante ley 2007/1774 del 17 de diciembre del 2007. Destacamos que se intercala a la regla ya existente -que sigue la norma del artículo 54 de la ley de 1930- un inciso primero que reconoce expresamente la action directe.

37 Corral (2013) pp. 439 y ss.; en el mismo sentido Contreras (2014) p. 433.

38 Corral (2013) p. 407; en el mismo sentido Contreras (2014) p. 439.

39 Corral (2013) p. 441.
} 
En una segunda etapa, y considerando que nuestro legislador no consagró de modo expreso la acción directa, algunos autores señalan que existen "elementos normativos que permiten deducir clara y categóricamente que la institución ha sido recepcionada” ${ }^{40}$. El primer elemento se encontraría en el inciso primero del artículo 570 del C.com. al disponer que "por el seguro de responsabilidad civil, el asegurador se obliga a indemnizar los daños y perjuicios causados a terceros, de los cuales sea civilmente responsable el asegurado, por un hecho y en los términos previstos en la póliza". Sobre este texto, Corral sostiene que "La obligación que surge del contrato, en consecuencia, no es la de pagar al asegurado aquello en lo que se condenó a indemnizar al tercero, sino directamente indemnizar, resarcir el daño causado por el asegurado [...]" ${ }^{31}$. Luego, se sostiene que la referida tesis quedaría reforzada en el inciso segundo del mismo artículo 570 del C.com ${ }^{42}$, al disponer que en el seguro de responsabilidad civil, el asegurador pagará la indemnización al tercero perjudicado, en virtud de una sentencia ejecutoriada, o de transacción judicial o extrajudicial celebrada por el asegurado con su consentimiento ${ }^{43}$.

Corral cierra su tesis señalando que "Si el asegurador de responsabilidad, una vez producido el siniestro, contrae la obligación de pagar la indemnización del daño al tercero perjudicado, es ineludible deducir que este adquiere un derecho personal o crédito en su contra. Se tratará, por tanto, de alguien que, no habiendo sido parte del contrato de seguro, adquiere un derecho subjetivo a reclamar la indemnización pactada entre asegurado y asegurador. Esta figura que constituye una excepción al principio del efecto relativo del contrato no es rara en el contrato de seguros ya que en su regulación siempre se ha contemplado la figura de 'beneficiarios' distintos del asegurado. El actual art. 513 letra c del Código de Comercio define como "beneficiario" a "el que, aun sin ser asegurado, tiene derecho a la indemnización en caso de siniestro" ${ }^{\text {. }}$.

Por su parte, Contreras adiciona lo siguiente. Recoge el texto del artículo 541 del C.com., en aquella parte que dispone para el caso concreto del seguro de responsabilidad civil, que el plazo de prescripción de las acciones que emanan del contrato de seguro no será inferior al de la acción que tenga el tercero perjudicado en contra del asegurado $^{45}$. Para este autor, la regla de prescripción del artículo 541 del C.com. "no puede sino ser interpretada en el sentido de que el legislador chileno está muy consciente que la acción para cobrar un seguro no puede extinguirse (prescribir), por la inacción del contratanteasegurado en hacerla exigible, sino que solamente una vez que se haya extinguido por la prescripción, la acción del tercero perjudicado que es el beneficiario del seguro" 46 .

La propuesta que hemos analizado, sobre la procedencia de la acción directa en contra del asegurador de responsabilidad civil bajo nuestro ordenamiento jurídico presenta, a nuestro parecer, ciertas interrogantes. Se trata, por lo demás, de justificar una excepción

40 Corral (2015) p. 407. En el mismo sentido Contreras (2014) p. 437.

41 Corral (2015) p. 407.

42 Corral (2015) p. 407.

43 Contreras (2014) p. 439.

${ }^{44}$ Corral (2015) pp. 407-408.

45 Contreras (2014) p. 439.

46 Contreras (2014) p. 440. 
al principio de efecto relativo ${ }^{47}$ de los contratos, ni mas ni menos. En el sentido indicado nos preguntamos, ¿cuál fue la real intención del legislador chileno en regulación del seguro de responsabilidad civil introducido mediante la ley 20.667? ¿Pueden ser considerados los terceros perjudicados como beneficiarios de la suma asegurada en un seguro de responsabilidad civil? ¿Cuál es el sentido del artículo 541 del C.com.?

A continuación, abordaremos las interrogantes que nos hemos formulado en orden a justificar nuestra propuesta de improcedencia de la acción directa del tercero perjudicado en contra del asegurador de responsabilidad civil, en el contexto de las modificación contenidas en la ley 20.667. Para ello, recurriremos a la historia de la ley, por un lado, y por el otro, a los textos normativos del C.com. y a la doctrina que definen y contextualizan la figura del beneficiario en el contrato de seguro.

\section{Fundamentos de la improcedencia de la acción directa en el Derecho} CHILENO

\subsection{Revisión de la historia de la ley 20.667}

Si bien nuestro legislador contemplaba en el proyecto de ley inicialmente una regulación de la acción directa, durante el primer trámite constitucional este mecanismo no fue considerado, más bien la norma fue expresamente eliminada ${ }^{48}$.

Revisemos brevemente la historia de la ley en este sentido. La moción parlamentaria expresa que "se instaura la acción directa del tercero perjudicado contra el asegurador en los seguros de responsabilidad civil, así como también, la regla de que aquél es al único a quien el asegurador puede pagar la indemnización”9. Luego, el texto normativo propuesto es el siguiente: "Art. 572. Derecho del tercero a demandar la indemnización. El tercero perjudicado tendrá acción directa en contra del asegurador para cobrar la indemnización" ${ }^{50}$.

El referido texto fue el aprobado por la Comisión de Economía de la Cámara de Diputados, no obstante en su discusión en sala el texto original del citado artículo 572 del proyecto de ley fue rechazado. Destaca la intervención del presidente de la Comisión de Economía, diputado Arenas, quien señalo que "En cuanto a la acción directa, si bien en teoría está muy bien intencionada, varios profesores, especialmente uno de la Universidad Católica, explicaba que, para que la acción directa fuera real y no produjera perjuicios más que beneficios, tenía que darse con una serie de requisitos en la legislación, y que todavía como país no tenemos" ${ }^{31}$.

Cuando el legislador estima que nuestro sistema no posee los presupuestos para consagrar la acción directa, apunta a la gradualidad en la implementación de mecanismos o instrumentos que buscan tutelar a quienes sufren daños provocados por conductas atribuibles jurídicamente a otro, tanto en la perspectiva de la responsabilidad civil como en la

\footnotetext{
Véanse PASANisi (1970) p. 189; Russo (2001) p. 30.

48 En el mismo sentido véase LaGos et al. (2014) p. 988.

49 Véase HISTORIA DE LA LEY 20.667, p. 15.

50 Véase HISTORIA DE LA LEY 20.667, p. 35.

51 Véase Historia de LA LEY 20.667, p. 201.
} 
dimensión de su aseguramiento, según referimos con anterioridad al abordar la evolución de la responsabilidad civil y el seguro ${ }^{52}$.

En el sentido indicado con anterioridad, es nuestra opinión, que el statu quo de nuestro sistema carece de los presupuestos necesarios para la implementación de una acción directa autónoma. Si bien en ciertas actividades de riesgos relevantes -en cuanto a su frecuencia e intensidad como los riesgos de circulación vehicular, accidentes del trabajo, responsabilidad civil profesional, por nombrar algunos ${ }^{53}$ - la responsabilidad civil se ha objetivado vía jurisprudencial, el paso a la incorporación de la obligatoriedad en la contratación de seguros de responsabilidad civil es aislada, para casos específicos. Una de las particularidades que plantea la doctrina, es precisamente el carácter obligatorio del seguro de responsabilidad civil en aquellos casos en los que se contempla acción directa; a ello adherimos ${ }^{54}$.

Lo que hemos señalado con anterioridad, coincide con los argumentos doctrinales que justifican la acción directa frente al principio de efecto relativo de los contratos, en concreto la función social o socialización del seguro de responsabilidad civil para ciertos riesgos, de modo que las potenciales víctimas del daño tengan una garantía de reparación por medio de este seguro obligatorio ${ }^{55}$. La denominada función social ${ }^{56}$ del seguro de responsabilidad civil, debe darse en todos los casos y no depender de un factor tan aleatorio como la contratación voluntaria de este tipo contractual. Como señala Díez-Picazo "no es lo mismo que una persona tenga que pagar una indemnización de un millón o que un millón de personas tengan que pagar indemnizaciones de una sola unidad de cuenta. Los aseguradores son ciertamente vehículos de distribución que pulverizan la indemnización que pagan repercutiéndola entre el resto de los asegurados que continúan pagando primas" 57 . En este sentido, el contrato de seguro de responsabilidad civil sería considerado como un instrumento de socialización del derecho de daños.

Concordante con lo que hemos expuesto, durante el segundo trámite constitucional, algunos parlamentarios insistieron en la posibilidad de instaurar la llamada acción directa.

52 En este sentido nuestra exposición en la Comisión de Economía de la Cámara de Diputados. Véase historia de la ley 20.667, pp. 85 y ss. Por su parte, Osvaldo Contreras en su intervención durante la tramitación de la ley 20.667, señaló: "La verdad es que sería ideal, expresó, contemplar además, la existencia de varios seguros obligatorios de RC para cubrir riesgos tales como la construcción (cuantos problemas podrían haberse resuelto si antes del terremoto del 27 de febrero hubiese existido), los vehículos motorizados, el transporte público y privado, terrestre, aéreo o marítimo, clínicas, espectáculos masivos, restaurantes, estaciones de servicio, talleres, etc.”. Véase Historia DE LA LEY 20.667, p. 100.

53 Véase ЈАСОВ (1974) p. 236.

54 En este sentido véase Iriarte y Casado (2013) p. 18. Cfr. Veiga (2013) p. 218. Los ordenamientos jurídicos como el italiano, portugués y alemán optaron por consagrar la acción directa para los casos de seguros obligatorios (coincide con los criterios de la CE). Los ordenamientos jurídicos francés y español han consagrado la acción directa tanto para los seguros obligatorios como voluntarios. Sin embargo, es ineludible advertir que estos países contemplan un sistema de seguros obligatorios para casos de actividades de riesgos relevantes, que se ha extendido cuantitativamente en el tiempo de manera exponencial. Véanse Bataller, Latorre y Olavarría (2007) p. 278; Beignier (2011) pp. 252 y ss.

55 En este mismo sentido véase Hebrero (2002) p. 75.

56 Esta función social del seguro de responsabilidad civil viene dada por la denominada socialización del derecho de daños. Véase Díez-Picazo (2011) p. 135 y ss. En este mismo sentido Hebrero (2002) p. 66.

57 Díez-Picazo (2011) p. 166. 
Ríos Ossa, Roberto "Improcedencia de la acción directa del tercero perjudicado en contra del asegurador..."

En este sentido, los senadores Frei y Rincón proponen la figura de la acción directa restringida para los seguros de responsabilidad civil obligatorios, indicación que finalmente fue retirada ${ }^{58}$. El texto fue el siguiente: "29.- De los Honorables Senadores señora Rincón y señor Frei, para consultar el siguiente artículo 572, nuevo: Art. 572. Acciones derivadas de seguros de responsabilidad civil obligatorios. En los seguros de responsabilidad civil cuya contratación sea exigida por normas legales o reglamentarias o por disposición de la autoridad, el tercero perjudicado tendrá acción directa en contra del asegurador para cobrar la indemnización".

No obstante lo señalado, la regulación del seguro de responsabilidad civil al ser rechazado el artículo 572 original, quedó desarticulada. Fue necesario incorporar una norma que contextualizara el seguro de responsabilidad civil, en especial el riesgo que asume el asegurador al celebrar este tipo contractual. Por esta razón, la definición del seguro de responsabilidad civil fue repuesta durante el segundo trámite constitucional por indicación de los senadores señora Rincón y señor Frei, indicación número 25. La historia de la Ley, señala lo siguiente ${ }^{59}$ :

"La indicación fue aprobada, con modificaciones, por la unanimidad de los miembros de la Comisión, Honorables Senadores señora Rincón y señores Frei, García, Lagos y Novoa. En virtud de ella se acordó la incorporación de dos nuevos artículos, 570 y 573 , al proyecto de ley, del tenor que se señalará en su oportunidad. El primero de ellos recoge, con una nueva redacción, los dos primeros incisos de la indicación; el segundo, en tanto, hace lo propio con los incisos tercero y cuarto de la misma proposición.

Intercalar el siguiente artículo 570, nuevo: Art. 570. Concepto. Por el seguro de responsabilidad civil, el asegurador se obliga a indemnizar los daños y perjuicios causados a terceros, de los cuales sea civilmente responsable el asegurado, por un hecho y en los términos previstos en la póliza.

En el seguro de responsabilidad civil, el asegurador pagará la indemnización al tercero perjudicado, en virtud de sentencia ejecutoriada, o de transacción judicial o extrajudicial celebrada por el asegurado con su consentimiento".

El legislador chileno recoge una definición que se repite en varios países europeos ${ }^{60}$, que han optado por regular el seguro de responsabilidad civil, describiendo el riesgo como una deuda de responsabilidad que pesa sobre el asegurado en razón de un daño causado a otro, al disponer en el artículo 570 definitivo que "Por el seguro de responsabilidad civil, el asegurador se obliga a indemnizar los daños y perjuicios causados a terceros, de los cuales sea civilmente responsable el asegurado". Se trata, como sostiene CAlZADA Conde de la

\footnotetext{
58 Véase Historia de LA LEY 20.667, pp. 372-373-410.

59 Véase Historia de LA LEY 20.667, pp. 407-420-421.

${ }^{60}$ Véanse arts. 73 de la Ley de Contrato de Seguros española; 124-3 Code des Assurances; 1917 Codice Civile. Osvaldo Contreras informó a la Comisión de Economía de la Cámara de Diputados, primer trámite constitucional, lo siguiente: "Por otra parte, la acción directa está contemplada expresamente, en muchísimos países y la tendencia mundial es a que se expanda su aplicación. Por citar solo a algunos, en Europa existe en España, Francia, Bélgica, Portugal con carácter general y en todo el resto de los países europeos para los seguros de RC obligatorios; en América en México, Colombia, Argentina, Paraguay, Perú, Bolivia, Venezuela y en el Proyecto de Nueva Ley sobre Contrato de Seguros de Brasil; así como en una gran parte de los Estados de USA, etc.”. Véase Historia de LA Ley 20.669, p. 99.
} 
"posibilidad de incurrir en responsabilidad frente a terceros y verse obligado, en consecuencia, a indemnizar los daños ocasionados" 61 o como sostienen LAMBERT-FAIVRE y LEVENEUR, en el seguro de responsabilidad civil "el objeto es la dette de responsabilité frente a la víctima" ${ }^{62}$.

De nuestro análisis de la historia de la ley 20.667 en cuanto a la regulación del seguro de responsabilidad civil, podemos concluir que la intención del legislador es clara en cuanto a la no instauración del mecanismo de reclamación denominado acción directa. En este sentido, es nuestro parecer que la intención del legislador no puede ser obviada por otras vías de interpretación inferiores en el orden de prelación de nuestro derecho común, en este caso desplazar la historia que nos entrega la voluntad del legislador por un ejercicio hermenéutico analógico. No estamos frente a un supuesto de ratio tácita, que permite al intérprete deducir motivos del legislador que subyacen supuestamente en la norma ${ }^{63}$. A nuestro juicio, la voluntad o intención del legislador fue claramente manifestada ${ }^{64}$, se trata de una ratio expresa que no puede se violentada o vulnerada.

\subsection{El tercero perjudicado como beneficiario del seguro de responsabilidad civil}

La figura del beneficiario se encuentra adscrita, más bien, tanto en su origen histórico como en la práctica aseguradora a los seguros de personas para los casos de muerte del asegurado $^{65}$. Es excepcional en los seguros de daños, y en los casos en los que opera esta figura para este tipo de seguros encontramos la exigencia del interés asegurable, como veremos más adelante.

En el contexto histórico, los seguros de personas para casos de muerte del asegurado se vieron enfrentados a la determinación de las reglas aplicables, por cuanto la prestación del asegurador surge por la ocurrencia de un siniestro, evento representado por la muerte del asegurado o como señala Tirado Suárez "en el seguro para caso de muerte sobre la propia vida, la prestación del asegurador se producía después del óbito del asegurado”. Por consiguiente, la determinación de quienes tienen derecho a la suma asegurada debía seguir, necesariamente, las reglas del derecho sucesorio o las donaciones entre vivos en aquellos casos en los que el asegurado contratante designaba expresamente a las personas que tendrían derecho a la suma asegurada a la llegada de su muerte ${ }^{66}$.

El desarrollo exponencial que experimentarán los seguros de vida -en especial en algunos países europeos como Francia- llevó a la jurisprudencia a recoger de la práctica aseguradora la figura del beneficiario con particularidades especiales, dando lugar a la creación jurisprudencial del seguro a favor de terceras personas, apartada de las reglas sucesorias o de

61 Calzada Conde (2005) p. 13.

62 Lambert-Faivre y LeVeneur (2011) p. 485.

63 Véase GuZmán Brito (2007) pp. 99 y ss.

64 En el mismo sentido véase Lagos et al. (2014) p. 993.

65 Véanse Contreras (2014) p. 646; Lagos et al. (2014) p. 995.

66 Tirado Suarez et al. (2010) pp. 2233 y ss. 
las donaciones entre vivos ${ }^{67}$. De este modo, la figura del beneficiario fue asimilada a la estipulación a favor de otro.

Revisada la historia de la ley 20.667 encontramos el vocablo beneficiario adscrito a los seguros de personas ${ }^{68}$. La sección tercera del Título VIII del Libro II del C.com. regula de manera específica al o los beneficiarios, su designación, revocación, derecho a la indemnización, entre otros aspectos. En la sección segunda que regula en específico los seguros de daños no hay referencia alguna al vocablo beneficiario. Lo que hemos señalado, coincide con nuestro análisis histórico sobre beneficiario como sujeto del contrato de seguro, que sin ser parte, tiene derecho a la indemnización una vez ocurrido el siniestro, especialmente en los seguros de personas ${ }^{69}$.

Otro de los factores que debemos considerar respecto del beneficiario se relaciona con el interés asegurable ${ }^{70}$. Considerando que el seguro de responsabilidad civil es de daños ${ }^{71}$, quien está en condiciones de exigir la suma asegurada o prestación del asegurador debe tener interés asegurable ${ }^{72}$. Para el caso de un seguro de responsabilidad civil -no obstante el fin tutelar a favor del tercero perjudicado- no debemos perder de vista que el interés asegurable se vincula al patrimonio del asegurado ${ }^{73}$, quien por la ocurrencia del siniestro puede experimentar una disminución patrimonial en razón de la deuda de responsabili$\mathrm{dad}^{74}$. Que duda cabe, los terceros perjudicados o víctimas del daño no poseen interés asegurable en el sentido que hemos indicado, pues, buscan la reparación de un daño propio ${ }^{75}$.

En cuanto al interés asegurable, el artículo 513 letra n) lo define como "aquel que tiene el asegurado en la no realización del riesgo, sin perjuicio de lo dispuesto en el artículo 589 en relación a los seguros de personas”. Revisada la historia de la ley, el proyecto contemplaba un texto que incluía al beneficiario, no obstante el legislador no lo consideró finalmente, recogiendo la indicación en este sentido del senador Lagos ${ }^{76}$. Luego, debemos considerar que nuestro legislador deja a salvo la exigencia del interés asegurable en los seguros de personas para el caso de muerte, acogiendo la doctrina que formula la exigencia de este presupuesto para este tipo de seguros, esencial para diferenciarlo de la apuesta. Con todo, lo que nos interesa formular es que el beneficiario debe tener interés asegurable para los casos del artículo 589 del C.com., presupuesto que no estará presente en el tercero perjudicado al momento de ocurrir riesgo de responsabilidad civil amparado en el contrato de seguro. Cómo puede entonces ser considerado acreedor de la suma asegurada.

\footnotetext{
67 Tirado SuÁrez et al. (2010) pp. 2233 y ss.

68 En este sentido véase pp. 18 y ss. de la HisTORIA DE LA LEY 20.667.

69 Dispone el inciso segundo del artículo 596 del C.com: Para todos los efectos legales, el derecho del beneficiario nace en el momento del siniestro previsto en la póliza, y a partir de él podrá reclamar del asegurador la prestación convenida. Véase ConTrERAS (2014) p. 650.

70 Véase Calzada Conde (2005) pp. 42 y ss.

71 Véase Calzada Conde (2005) p. 18; Chagny y Pedrix (2009) p. 335.

72 Gallardo (2015) p. 495.

73 Gallardo (2015) p. 495.

74 En este mismo sentido véase Díaz Granado (2008) p. 293.

75 Véanse Veiga (2013) pp. 31 y ss.; Lagos et al. (2014) p. 995.

76 Sobre el detalle del debate parlamentario sobre la exclusión del vocablo beneficiario en el artículo $513 \mathrm{~m}$ ) véase historia de la ley pp. 379 y ss.
} 
La falta de interés asegurable a la época de ocurrir el siniestro impide reclamar la indemnización, según reza el artículo 546 del C.com.

Unido a los argumentos históricos y sobre el interés asegurable vistos con anterioridad, es ineludible precisar que el beneficiario es un sujeto integrado por el contratante o asegurado al contrato, no obstante no haber prestado su consentimiento en la celebración del seguro. En esta perfectiva es un tercero ${ }^{77}$. En esta dimensión y con los matices de diferencia que se observan entre el artículo 1449 del C.c. y la regulación de C.com. sobre el beneficiario -especialmente en materia de revocación-, se asimila -con algunas diferencias- a la estipulación a favor de otro, que exige pacto expreso ${ }^{78}$. Es por esta razón que la ley al referirse al beneficiario lo hace en un contexto de designación. Basta, por ejemplo, dar lectura al artículo 518 sobre la menciones mínimas que debe contener toda póliza de seguros, entre ellas la individualización o forma de determinar al beneficiario en aquellos casos en que ha sido designado. En este contexto, nos parece útil la afirmación de ABravaNEL-JOLLY, quien señala que en el seguro de responsabilidad civil "asegurado y beneficiario son la misma persona"79, es el asegurado quien se beneficia con el contrato frente a la deuda de responsabilidad. Por el contrario, si el tercero perjudicado es considerado beneficiario al ocurrir el siniestro pasa a ser un asegurado más para los efectos de la prestación del asegurador, por lo que su derecho a la suma asegurada es de origen contractual ${ }^{80}$. Por su parte, la acción directa es una acción de fuente legal -no convencional-conferida a la víctima para dirigirse en contra del asegurador ${ }^{81}$.

Con todo, y sobre esta relación seguro de responsabilidad civil y beneficiario, es ineludible señalar que la doctrina dominante sostiene que este tipo de seguro no constituye un contrato a favor de un tercero ${ }^{82}$. Reglero CAMpos refiere tres razones: primero, por cuanto la voluntad de los contratantes no apunta ni a favorecer a un tercero ni a conceder a favor de este último una acción directa; segundo, hay ciertos presupuestos propios del contrato a favor de terceros que se apartan de la figura del beneficiario como la aceptación y la revocación; y tercero, en el contrato a favor de tercero, lo normal es la determinación en la persona favorecida con la estipulación, contrario a lo que ocurren en el caso del seguro de responsabilidad civil que se caracteriza por la indeterminación de la víctima ${ }^{83}$. En este mismo sentido, Veiga señala que "No estamos ante un contrato a favor de tercero, y no es el tercero quien interesa o tiene interés en el contrato de seguro, sino el asegurado, eventual dañante si se acaba produciendo un daño del que deba responder" ${ }^{84}$.

En consecuencia, a nuestro juicio, no podemos inferir que la ley considera a los terceros perjudicados como beneficiarios, para los efectos de introducir el mecanismo de la

7 En el mismo sentido véase Hoyl y Ruiz - Tagle (2014) p. 49.

78 Ríos (2015) p. 64. Véase Contreras (2014) p. 646; Hoyl y Ruiz -Tagle (2014) p. 50.

79 Abravanel-Jolly (2013) p. 258. En el mismo sentido véase Lagos et al. (2014) p. 996.

80 Véase en este sentido Lima (2010) p. 648.

81 Abravanel-Jolly (2013) p. 258.

82 Por todos Reglero Campos (2006) p. 728. Cfr Diaz Granado (2008) p. 316.

83 Reglero Campos (2006) p. 729.

$84 \operatorname{VeIga}(2013)$ p. 21. 
acción directa en nuestro ordenamiento jurídico, en su estado actual ${ }^{85}$. Menos, podríamos vía analogía integradora ${ }^{86}$ (legis o iuris) completar un supuesto vacío o laguna inexistente.

\subsection{La regla especial de prescripción del artículo 541 del C.com}

Terminamos haciéndonos cargo del argumento expuesto por ConTreras y que hemos detallado supra en el contexto del artículo 541 del C.com. A nuestro parecer, lo que busca el legislador en el caso del citado artículo 541 del C.com. -a propósito de la prescripción en el seguro de responsabilidad civil-, es equiparar el plazo de prescripción de la acción de responsabilidad civil al plazo de prescripción de la acción de cumplimiento o de indemnización -según los casos-, que posee el asegurado o contratante y que emana de la celebración del contrato de seguro. En caso contrario, podríamos vernos enfrentados a un supuesto de cobertura insuficiente o inexistente, ya que vencido el plazo para exigir el cumplimiento del contrato de seguro, podría el asegurado enfrentar un juicio de responsabilidad por un hecho previsto en la póliza. Unido a lo anterior, si revisamos la historia de la ley, podemos verificar que la norma que hemos referido fue incluida por indicación del Senador García al concluir el segundo trámite constitucional, estado de avance del proyecto que ya no contemplaba la acción directa ${ }^{87}$.

Consecuencia de lo que hemos señalado, el texto del citado artículo 541 del C.com. no contiene elementos que permitan trastrocar la expresa voluntad del legislador, con el fin de justificar la procedencia de la acción directa en contra del asegurador de responsabilidad civil en el estado actual de nuestro ordenamiento jurídico.

\section{CONCLUSIÓN}

De lo que hemos expuesto, podemos extraer las siguientes conclusiones:

La historia fidedigna del establecimiento de los artículos 570 y siguientes del C.com, demuestra que la intención manifestada por el legislador fue la de no introducir en nuestro ordenamiento jurídico la acción directa del tercero perjudicado en contra del asegurador de responsabilidad civil.

Por otra parte, la figura del beneficiario tienen particularidades especiales en el contrato de seguro. Se trata de una figura excepcional en los seguros de daños, más bien adscrita a los seguros de personas. En el caso particular de un seguro de responsabilidad civil, en su categoría de seguro de daños la exigencia de existir interés asegurable al momento de la ocurrencia del siniestro es ineludible, supuesto que no concurre en el caso de los terceros perjudicados calificados como beneficiarios que carecen de tal interés.

La analogía como método de interpretación, de un caso expreso, aunque oculto, oscuro o ambiguo, consiste en asimilar racionalmente el contenido o sentido claro y conocido de otra ley, y es una regla residual que no debe ser aplicada para justificar la proceden-

\footnotetext{
85 En sentido contrario Corral (2013) pp. 441 y ss.

86 Completar vía analogía integradora implicaría extender la regla del artículo 513 letra c) como caso expreso, al artículo 570 como caso omissus. En consecuencia, cuando el artículo 570 recurre a la voz tercero debemos entender que se trata de aquel que sin ser asegurado tiene derecho a la indemnización.

87 Véase Historia de ley 20.667, p. 369. Véase Hoyl y Ruiz-Tagle (2014) p. 86.
} 
cia de la acción directa del tercero perjudicado en contra del asegurador de responsabilidad civil de modo implícito o subyacente en la ley. Ello trastroca la voluntad del legislador.

Por consiguiente, nuestro ordenamiento jurídico no contempla, en su estado actual, el instrumento tutelar a favor de las víctimas del daño, denominado acción directa.

\section{BIBLIOGRAFÍA CITADA}

Abravanel-jolly, Sabine (2013): Droit des assurances (Toulouse, Ellipses).

Achurra, Juan (2005): Derecho de Seguros. Escritos de Juan Achurra Larraín Tomo III.

(Santiago, Universidad de los Andes, Colección Jurídica $\mathrm{N}^{\circ} 7$ ).

Alpa, Guido y Bessone, Mario (2001): La responsabilità civile (Milano, Guiffrè Editore).

Arellano, Sergio (2013): Ley de seguros (Santiago, Thomson-Reuters).

BaEza, Sergio (2001): El Seguro (Santiago, Editorial Jurídica de Chile, cuarta edición).

Barros Bourie, Enrique (2007): Tratado de responsabilidad civil extracontractual (Santiago,

Editorial Jurídica de Chile).

Barrientos, Marcelo (2015): “Artículo 570, El seguro de responsabilidad civil”, en Ríos

Roberto (director) y SCHIEle, Carolina (editora), El Contrato de seguro, Comentarios al

Título VIII Libro II del Código de Comercio (Santiago, Thomson Reuters) pp. 617-629.

Bataller, Juan, Latorre, Nuria y Olavarria, Jesús (2007): Derecho de los Seguros Privados

(Madrid, Editorial Marcial Pons).

Beignier, Bernard (2011): Droit des assurances (París, Montchrestein-Lextenso èditons).

Bottiglieri, Enrico (2010): Il Códice civile, comentario, Dell'assicurazione contro i danni

(Milano, Guiffrè Editore).

Calzada Conde, María de los Ángeles (1983): El seguro voluntario de responsabilidad Civil (Madrid, Montecorvo).

Calzada Conde, María de los Ángeles (2005): El seguro de responsabilidad civil (Navarra, Thomson-Reuters).

Carboni, Bruno (1972): "Appunti in tema di azionne diretta del danneggiato verso l'assicuratore de veicolo condotto dal danneggiante", Assicurazioni, Rivista di Diritto, Economia e Finanza delle Assicurazioni Private, Fasc. No 6: pp. 494-509.

Cavallo, Rossella (2007): Responsabilitá e Assicurazione (Milano, Guifré Editore, segunda edición).

Clavero, Manuel (1995): La acción directa del perjudicado contra el asegurador de responsabilidad (Madrid, Tecnos).

Contreras, Osvaldo (2014): Derecho de seguros (Santiago, Thomson-Reuters, segunda edición).

Corral, Hernán (2013): Lecciones de responsabilidad civil extracontractual (Santiago, Thomson Reuters, segunda edición).

Corral, Hernán (2015): "La interposición de la acción directa implícita del tercero perjudicado en contra del asegurador de responsabilidad civil en el nuevo régimen de seguros chileno", Revista Chilena de Derecho, vol. 42, No 2: pp. 397-422.

Chagny, Muriel y Pedrix, Louis (2009): Droit des assurances (París, L.G.D.J Lextenso Éditons). 
Díaz Granados, Juan Manuel (2008): Las acciones relacionadas con el seguro de responsabilidad civil (Madrid, Fundación Mapfre).

Díez-Picazo, Luis (2011): Fundamentos de Derecho Civil Patrimonial V. La responsabilidad civil extracontractual (Madrid, Civitas-Thomson Reuters).

Donati, Antigono (1954): Trattato del Diritto delle Assicurazionni Private, volume secondo (Milano, Editore Guiffré).

EICHLER, Hermann (1966): Versicherungsrecht (Karlsruhe, Verlag Versidierungswirtsdiaft).

Gallardo, Marcelo (2015): “Artículo 546, El interés asegurable en los seguros de daños”, en Ríos, Roberto (director) y Schiele, Carolina (editora), El Contrato de seguro, Comentarios al Título VIII Libro II del Código de Comercio (Santiago, Thomson Reuters) pp. 493-497.

Garrigues, Joaquín (1982): Contrato de Seguro Terrestre (Madrid).

GuZmán Brito, Alejandro (2007): Reglas del Código Civil de Chile sobre interpretación de las leyes (Santiago, LexisNexis).

Haperling, Isaac y Barbato, Nicolás (2003): Seguros, Exposición Critica de las Leyes 17.418, 20.091 y 22.400 (Buenos Aires, LexisNexis).

Hebrero, José Ignacio (2002): El aseguramiento de la responsabilidad civil por daños al medio ambiente (Madrid, Dykinson).

HoYl, Rodrigo y Ruiz-Tagle, Carlos (2014): El Contrato de seguro, análisis de las cobertura de vida e incendio en la nueva ley 20.667 (Santiago, Thomson-Reuters).

IRIARTE, Jose Luis y CASADO, Marta (2013): La acción directa del perjudicado en el ordenamiento jurídico comunitario (Madrid, Fundación Mapfre).

JaCOB, Nicolás (1974): "Les Assurances", Assurances et Responsabilitè civil, Vol. II (París, Dalloz).

Jiménez, Pilar (2009): "Acción directa y protección del perjudicado en el reglamento Roma II”, Revista Española de Seguros, No 140: pp. 741-765.

LaGos, Osvaldo (2014): “¿Se reconoce la acción directa de la víctima contra el asegurador en la legislación chilena?”, en Estudios de Derecho Civil X (Santiago, Thomson Reuters) pp. 987-997.

Lambert-Faiure, Yvonne y Levneur, Laurent (2005): Droit des Assurances. (París, Dalloz, duodécima edición).

Lambert-Faiure, Yvonne y Levneur, Laurent (2011): Droit des Assurances. (París, Dalloz, décimo-tercera edición).

La Torre, Antonio (1971): "Azione diretta e assicurazione”, Assicurazioni, Rivista di Diritto, Economia e Finanza delle Assicurazioni Private, vol. 38: pp. 526-611.

Lima, Margarida (2010): Contrato de seguro e terceiros (Coimbra, Coimbra Editora).

López-Coвo, Claudio (1999): "El seguro de responsabilidad civil general en el umbral del siglo XX. Últimas Tendencias”, Revista de Responsabilidad Civil, Circulación y Seguro, sección $1^{\mathrm{a}}$ : pp. 4-12.

MaYauX, Luc (2011): Les grandes questions du droit des assurances (París, L.G.D.J Lextenso Éditons).

Mazeaud, Henri y León y Tunc, André (1963): Tratado teórico y práctico de la responsabilidad civil delictual y contractual, t. III, vol. II (trad. Luis Alcalá-Zamora, Buenos Aires, Ediciones Jurídicas Europa-América). 
Olivencia, Manuel (2002): Cuestiones actuales de derecho de seguros. (Barcelona, AtelierEspaña).

PASANISI, Emilio (1970): "I Diritti del terzo verso l'assicuratore", Assicurazioni Rivista di Diritto, Economia e Finanza delle Assicurazioni Private, vol. 37: pp. 189-277.

Picard, Maurice y Besson, Andre (1964): Les Assurances Terrestres en Droit Francais (París, Librería General de Derecho y Jurisprudencia, R. Pichon y R Duranz Auzias).

Reglero Campos, Fernando (2006): "El seguro de responsabilidad civil”, en Tratado de Responsabilidad Civil. (Madrid, Thomson-Aranzadi) pp. 722-838.

Ríos, Roberto (2010): "Modificaciones al Código de Comercio Chileno: Artículo 513 inciso segundo - El Riesgo", Revista Chilena de Derecho, vol. 37, N³: pp. 505-520.

Ríos, Roberto (2015): El Contrato de seguro, Comentarios al Título VIII Libro II del Código de Comercio, Capitulo I (Santiago, Thomson Reuters) pp. 5-28.

Russo, Chantal (2001): De l'assurance de responsabilité a l'assurance directe. (París, Dalloz).

Sánchez Calero, Fernando (2010): "El seguro de responsabilidad civil", en Ley de Contrato de Seguro (Madrid, Aranzadi, cuarta edición) pp. 1529-1800.

STiglitz, Rubén (2005): Derecho de Seguros: Seguro contra la responsabilidad civil, Tomo IV, (Buenos Aires, Editorial La Ley, cuarta edición).

Tirado SuÁrez, Francisco Javier (2010): "Artículo 87, El beneficiario", en Sánchez CALERO, Fernando et al, Ley de contrato de seguro (Madrid, Aranzadi, cuarta edición) pp. 2300-2321.

Trimarchi, Pietro (1961): Rischo e Responsabilità Civile (Milano, Guiffrè Editore).

VeIga Copo, Abel (2013): La acción directa del tercero perjudicado en los seguros de responsabilidad civil (Navarra, Thomson-Reuters-Civitas).

Viterbo, Camilo (1944): El Seguro de Responsabilidad Civil (traducción de Mauricio L. Yardola, Buenos Aires, Depalma).

Volpe, Giovanna (2010): Comentario Breve al Diritto delle Assicurazioni (Milano, Cedam). 